\title{
Transformational Relationship with Employee Creativity: The Moderating Effect of Knowledge Sharing and Mediating Effect of Creative Self-Efficacy
}

\begin{abstract}
Naveen Asad ${ }^{a}$, Hammad Bin Azam Hashmi $^{b}$, Mishal Nasirc, Adeel Khalid ${ }^{\text {, }}$ Aftab Ahmad ${ }^{e^{*},}$, Department of Management Sciences, COMSATS University Islamabad, Pakistan. ${ }^{b}$ Department of Business Administration, Faculty of Management Sciences, ILMA University, Karachi, Pakistan. ${ }^{\mathrm{c} D e p a r t m e n t}$ of Management Sciences, COMSATS University Islamabad, Pakistan. ${ }^{\mathrm{d} N U S T}$ Business School, National University of Sciences and Technology (NUST), Islamabad, Pakistan. 'Department of Electrical Engineering, NFC Institute of Engineering and Fertilizers Research (NFC-IEFR), Faisalabad, Pakistan. *Corresponding Author, Email: $\quad$ Naveenasad05@gmail.com, bHammad.shah046@gmail.com, dAdeel.khalid@nbs.nust.edu.pk, ${ }^{\mathrm{d}}$ aftabahmadrao@gmail.com
\end{abstract}

Sustainable competitive advantage is the ultimate goal of numerous creative oriented firms. Therefore, this study's purpose is to investigate the relationship amongst transformational leadership and employee creative performance with the intervening mechanism of creative self-efficacy, furthermore, this study's purpose is to examine the knowledge sharing culture moderating role amongst transformational leadership and creative self-efficacy. A quantitative survey methodology was used for data collection, and 150 questionnaires have been circulated to employees employed in the private banking sector situated within twin city premises. This study's result indicated that transformational leadership and employee creative performance have significant relationships with each other, moreover, creative self-efficacy mediates amongst that relationship. Furthermore, knowledge sharing culture does not moderate amongst transformational leadership and creative selfefficacy. Practical implications and limitations have been discussed. Likewise, the future direction is also recommended in this study.

Key words: Transformational leadership, Knowledge Sharing Culture, Creative SelfEfficacy, Employee Creative Performance 


\section{Introduction}

In the modern era, innovative firms are striving hard in attaining a competitive edge, which is impossible without creative employees. Employee creative performance is considered valuable for firm productivity and survival. For example, the banking sector of Pakistan has emerged as a key sector. It has put the entire Pakistan economy at the centre of attention and has played a significant role in raising and maintaining the national GDP. This sector is facing the challenge of increasing employee creativity. It is of vital importance in deciding reliable and appropriate solutions to complicated and unclear problems (Golden and Shriner, 2017). As employees are considered an important factor in the banking sector, the organizational leaders are facing issues in balancing the important aspect such as motivating the employees and develop creative skills to increase their performance. There is a need to develop a creative environment in the organization to attain a competitive edge (Ferreira, Coelho, and Moutinho, 2020). Researchers like Santoro, Bresciani, and Papa (2020) concluded that for maintaining the success and growth of organizations, employee creativity, and creative self-efficacy should be supported. Employee creativity requires employees to get out of their comfort zone for thinking about unconventional and productive ideas (Guo et al., 2018). So, the organization which is dependent on employee creativity must encourage their employee to develop productive and unique ideas with high enthusiasm and interest (Kremer, Villamor and Aguinis, 2019). According to researchers, creativity among employees is developed with a transformational leadership style. The leadership works to enhance the creative abilities to create solutions for the issues. According to Bass (1985), the transformational leadership have a deceptive vision for the organization and have their skills for encouraging the employees for starting the development of innovative thinking and creative solutions for the problems. The concept of transformational leadership has developed attention for theoretical as well as a practical perspective which is based on the instrumental exchange process. These leaders encourage their employees to deliver the results which are beyond their expected level. This is possible by raising the higher levels of values and beliefs (Salem, Walumbwa, Misati, Babalola, and Kim, 2020). This research, therefore, tries to observe the relationship of transformational leadership with employee creativity.

Employees focus on thinking about creative ideas if they have a high tendency to believe in creative capabilities (Lee, Yun, Lee, and Lee, 2018). It is one of the significant mediating mechanisms which creates a secure connection amongst transformational leadership and employee creativity. Moreover, another organizational aspect that is of critical importance in influencing employees to be creative is knowledge sharing (Mittal and Dhar, 2015). It deals with expressing or discussing ideas or information with the preferred person. According to researches, knowledge-sharing behavior can impact the individual creativity. Mittal and Dhar (2015) found that for predicting employee creativity, creative self-efficacy plays mediating role. Knowledge sharing culture is that factor which is extremely important in upgrading employee creativity (Kremer, Vilamor, and Aguinis, 2019). The leader with transformative behavior can only encourage the employee to be confident in their creative capabilities and 
have high self-efficacy while performing the creative task when knowledge sharing culture will be promoted in which not only leader share knowledge to the employee regarding creativity but also encourage individual to share creative based ideas and knowledge, essential for both organization and employee performance (Husseini, Beltagi and Moizer, 2019).

Banking is one of the service industries that seek to find unique ways of serving clients (Alam, 2013). Because of global developments in the banking processes, the banking industry faces increased competition (Fujii et al., 2014). Banking practitioners must therefore be able to attract and maintain new customers through the delivery of outstanding services. In modern organizations such as banks, competitive business environment imposes a need for long-lasting improvement of quality of products, services, and business processes, as well as the need for conducting continuous training and development of their employees, like in banking institutions they more focus on "quality of service", which implies high job performance of employees referring to employee engagement and job involvement of employees working in the banking sector. Johnson et al. (1996) reported that in the service sector, the commodity is information itself, and the dominant form of capital is human capital is necessary. So, an effective workforce is essential in the banking sector which leads towards better performance of this sector. However, few researches have addressed the creativity issues through creative self-efficacy and knowledge sharing by using the perspective of employees working in the banking sector in Pakistan. This research examines the impact of transformational leadership can play important role in the development of creative self-efficacy on employees working in the banking sector of Pakistan. The banks play important role in increasing the GDP of developing countries like Pakistan. The researches show that banks play important role in the economic growth of Pakistan. This specific study will add to the prevailing employee creativity literature by examining knowledge sharing moderating role amongst transformational leadership and creative self-efficacy, which consequently influence employee creativity. Moreover, this will have practical implications for the manager of the private banking sector and help them in understanding, developing, and promoting knowledge sharing culture. Nevertheless, the study will also have practical implications for employees to believe in their creative capabilities necessary for their creative performance. Hence this research is set to investigate the impact of leader-member exchange on the job performance of the employee and how it is affected by employee engagement and job involvement.

\section{Literature Review}

\section{Social learning theory}

The social learning theory explains that people learn in the organizations by observing the behaviour of self and others (Bandura, 1977). The followers learn how to creatively think and come up with solutions for generating new ideas by observing their leaders and their intellectual stimulation (Eisenbeiß and Boerner, 2013; Mittal and Dhar, 2015). The employees 
can observe from knowledge sharing provided in the organization which favour the creative ideas by experiencing the individualized consideration of transformational leaders (Bass, 1985). This process of knowledge sharing can help the employees to develop creativity and motivate the employees to develop challenging goals (Bandura, 1986). The transformational leaders can increase motivation in employees for creativity and this process leads to develop creative self-efficacy among employees (Koh, Lee and Joshi, 2019) and help to minimize the obstacles during work, motivate them for creative pursuits and developing higher creative performance (Farmer, 2003).

\section{Transformational leadership}

Transformational leadership is a famous concept in the literature regarding management due to its relational as well as motivational style (Gardner et al., 1998). The idea of transformational leadership has been conceived by Bums (1978). He distinguished the characteristics of transactional leadership from those of transformational leadership. Transformational leaders usually motivate their subordinates to work in a creative way and for a long time, thus produce more effective outcomes than expectations (Bass, 1985). Transformational leaders establish the effective relations with their subordinates and therefore, transform, encourage as well as promote the ethical and creative aspirations of their followers. Bass (1994) also argued that the transformational leaders are the ones who aim to enhance potential, good value systems, motivation, and higher need in their subordinates (Andriani, Kesumawati, and Kristiawan, 2018). This motivation encourages the employees to work with unity, transform their beliefs, and instead of looking at their interests, they should work for organizational interests. This leadership style mostly suits organizations that have a dynamic environment. The style of transformational leadership is the combination of various leaders and it consists of four constructs i.e., charisma/idealized influence, individualized consideration, intellectual stimulation, and inspirational motivation. Transformational leaders also enhance the creativity of their subordinates by engaging them in intellectual stimulation. These leaders are role models as well as inspiration for their subordinates. Therefore, if these leaders should be trained then they can improve the creativity level of their employees (Buil, Martínez and Matute, 2019).

\section{Employee Creativity}

Creativity refers to the production or development of innovative as well as useful ideas that improve the effectiveness and productivity of processes (Oldham and Cummings, 1996). However, the employee creativity is the one in which individuals generate the useful and innovative ideas, procedures and product that works as raw material for further innovations. Creativity has been derived by individuals due to their skills, expertise, and creative thinking that is based on their experience as well as formal education. In the current business environment, creative employees have been made very essential for the firms to accomplish the competitive advantage. It is a process in which employees transform their routine behavior 
to accomplish some creative outcomes. As per Kremer, Villamor, and Aguinis (2019) creative employees prove as a value addition for the organizations where leadership plays a significant role.

\section{Knowledge Sharing}

The resource-based theories suggest that to maintain a competitive position in the market, organizations acquire those strategic resources that are valuable and are hard to replicate. One of the factors that prove as the main source in promoting employee innovation is knowledge (Liao and $\mathrm{Wu}, 2010)$. The education, as well as experience of employees, are one of the important organizational resources to promote innovation, while knowledge of employees is hard to change, and promoting the behavior of knowledge sharing in organizations is also hard. The process of knowledge sharing includes exchanging the knowledge with others and use it to derive novel and creative ideas. Moreover, the knowledge-sharing behavior in the organization improves the capacity of employees to generate more creative ideas (Yazhou and Jian, 2013).

\section{Creative Self-Efficacy}

Self-efficacy has been defined by Bandura (1977) as the individual confidence in accomplishing a goal. Creative Self Efficacy is the characteristics of individuals regarding their competencies to innovate. It is also described as an internal and sustaining force that compels individuals to generate productive and creative outcomes (Alameri et al., 2019). Moreover, it also encourages the employees to cope with challenging situations through creative strategies. It reflects the confidence of an individual about his/ her aptitude to accomplish a particular task in a creative way. In addition, knowledge sharing behavior shapes the employee's self-efficacy and their ability for innovations.

\section{Transformational leadership and employee creative performance}

Creativity is defined as the capability to develop new thoughts and productive results for problems (Amabile, 1983, 1988). Creativity is not only crucial for satisfying customers but also considered so crucial for organization success and survival (Guo et al., 2018). Some researcher believes that creativity requires the employee to develop the new or practical solution of a problem apart from generating ideas of new product and services (Hirst et al., 2009). It's not only essential for an employee to have his characteristics for improving his creative performance, but also organizational factors matter a lot in enhancing his creative performance. There are many organizational factors that can positively impact employee creative performance. One of them is transformational leadership which is discussed as important organizational part that influence follower by broadening or elevating follower goal and providing them with confidence to perform beyond the expectation specified in the implicit and explicit exchange agreement. Previous theories identified that this leadership aspect helps 
in guiding subordinate to increase their creative potential. Employee creative performance will improve when employers adopt transformational behaviour (Ma and Jiang, 2018).

Bass (1985) identified theoretically that this leadership type contains four dimensions such as intellectual stimulation (encourages follower to adopt non-traditional thinking approach while solving the problem, express new ideas, try to rethink about ideas and give reasoning behind that ideas) which is considered to be essential dimension for promoting employee creativity. According to Hermann and Felfe (2013) also individualized consideration (focus on employee personal needs and encourage them to change their viewpoint) play an essential role in refining employee creative performance, thinking about unique and non- linear ideas is impossible without that dimension (Wang and Rode, 2010) lastly inspirational motivation (leader ability to speak to a follower with some confidence, enthusiasm, and motivation) and idealized influence (influence follower to overcome their problems through creative ideas, they are trusted and respected by their follower) are considered to be productive in enhancing intrinsic motivation level of employee which results in improving creative performance (Tse, To and Chiu, 2018). These behavioural factors of leader help to develop creativity among employees which ultimately result in motiving employees and act as a source to promote creativity among them (Henker, Sonnentag and Unger, 2015). Therefore, following hypothesis is proposed:

\section{H1: Transformational leadership is positively related with employee creative performance.}

\section{Transformational leadership and Creative Self-efficacy}

Bandura (1986) in his social cognitive theory explained self-efficacy which was further explained by Tierney and farmer (2002) with the perspective of creativity as the confidence of a person to generate unconventional and productive ideas necessary for organization. As an essential aspect of creativity, it requires individuals to be highly confident while doing creative tasks (Mittal and Dhar, 2015). It is found that transformational leaders through four dimensions help in increasing creative self-efficacy of employee. When the leader supports or recognize creative ideas of employee and encourage them to be future-oriented (Wu and Parker, 2017). The leader provides them different task which is not only productive for organization but also fruitful for them, then this results in up gradation of employee self-belief in his creative yet conducive knowledge, skills and competencies (Chaubey, Sahoo and Khatri, 2019). Moreover, (Wang, Tsai and Tsai, 2014) suggested that supervisor having transformational behavior helps in increasing self-efficacy and push employees to improve competency and enable them to be confident in creative capabilities. The research conducted by Afsar and Masood (2018) found a positive relationship between transformational leadership and creative self-efficacy. Therefore, following hypothesis is proposed:

H2: Transformational leadership is positively related with creative self-efficacy. 


\section{Mediating role of Creative Self-efficacy}

Tierney and Farmer (2002) defined creative self-efficacy as individual self-belief to generate novel and productive ideas are considered to be the significant motivator behind employee creativity as an employee with excessive creative self- efficacy become extremely confident while performing the non-conventional task (Tierney and Farmer, 2011). According to Gist and Mitchell (1992) point of view, employee self-efficacy leads them to think more creative solutions to problems. However, employee creative self-efficacy is found to be influenced by supervisor with transformative behaviours like individualized thought, inspirational motivation, idealized effect. According to Mittal and Dhar (2015) transformative leader significantly increase creative self-efficacy of employee by supporting as well as recognizing their creative ideas moreover encourage them to be future-oriented and generate creative ideas and also providing them a challenging and unique task which are not only productive for organization but also fruitful for them which in result enhance creative performance of follower. The transformational leaders take proactive steps for development of creative thoughts and they expect same from the employees as well. Therefore, the leaders who implement transformational leadership encourage creativity in employees by developing creative self-efficacy. Hence this factor will most likely mediate amongst transformational leadership and employee creativity. Therefore, following hypothesis is proposed:

\section{H3: Creative self-efficacy mediates the relationship amongst transformational leadership and employee creative performance.}

\section{Moderating role of Knowledge Sharing}

The knowledge sharing is based on practice of sharing ideas from interaction and communication between people. Knowledge sharing is defined as "a social interaction culture, involving the exchange of employee knowledge, experiences, and skills through the whole department or organization" (Lin, 2007, p. 315), entail employee to not only seek knowledge but also share knowledge with supervisor for escalating creative ideas. Knowledge sharing is a process of sharing information and data which can elevate the performance of employees at work, including learning, decision making and problem solving. Creativity is a result of knowledge formation and sharing (Wang, 2010). Kim and Park (2015) studied the impact of knowledge sharing for developing employee creativity. This has encouraged recent studies of creativity to highlight the importance of sharing information in mobilising creative efforts in employees. Apart from that, leadership is of essential importance in increasing knowledge sharing culture, and past studies have suggested that Transformational leader helps in adopting knowledge sharing culture through pushing employees to express knowledge regarding their creative ideas (Carmeli et al., 2011). The leader attentively listens toward their creative ideas, provides support, and motivate them to be confident in their creative knowledge skill and capabilities. The past article has also shown that knowledge sharing culture is identified to be major factor to upgrade creative self-efficacy prior studies suggest that individual feel 
confident by not only obtaining creative based knowledge from the leader but also expressing their knowledge regarding creativity (Hu, Bei, Zhou, and Yidan, 2016). Moreover, transformational leadership is associated with knowledge sharing culture, which subsequently enhances individual self-belief in creative capabilities (Li et al., 2014; Mittal and Dhar, 2015). Therefore, this proposed that knowledge sharing will most likely moderates amongst transformational leadership and creative self- efficacy.

H4: Knowledge Sharing Moderates Transformational Leadership relationship with Creative Self- Efficacy in such a way that both have a stronger relationship when it is high instead of low.

\section{Research Model}

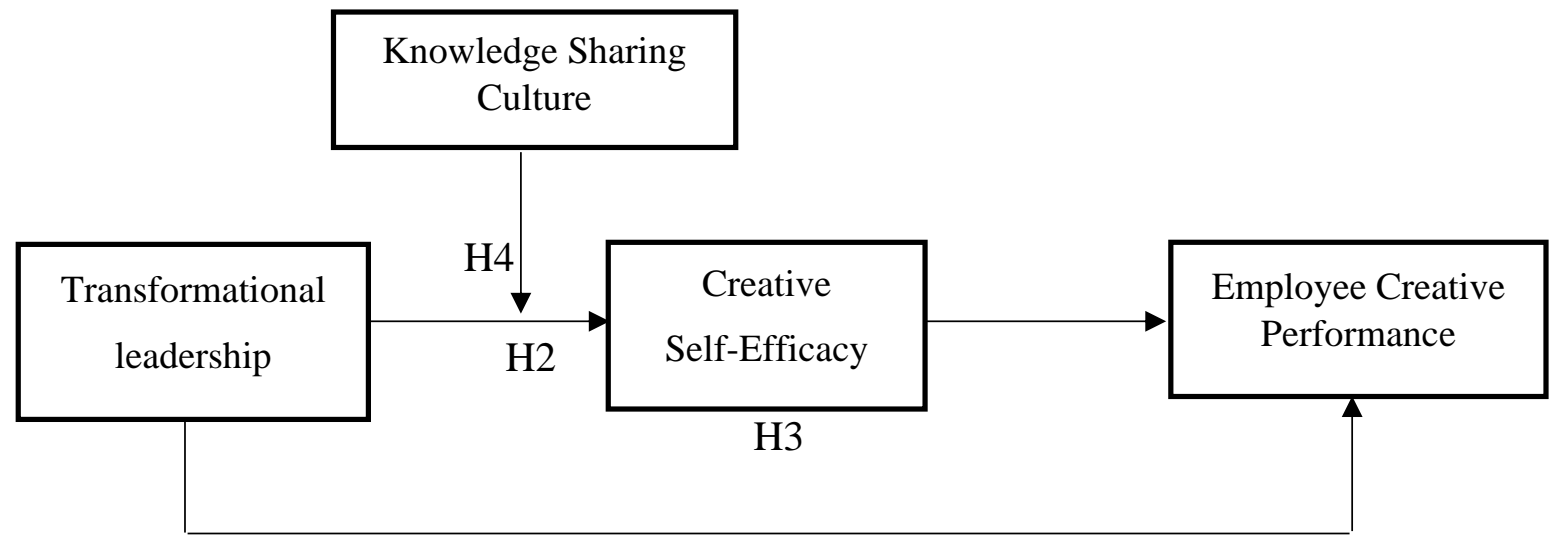

H1

Figure 1 Research Model

\section{Methodology}

\section{Participants and Procedure:}

The aim of this research was to examine the relationship between transformational leadership, creative self-efficacy, knowledge sharing and employee creativity from the perceptive employees working in banking sector of Pakistan. The study has targeted banking sector of Pakistan specifically private banks which are 22 in total all across Pakistan because they have contributed 57.37\% GDP in Pakistan total economy (World Bank, 2019) and also private banks within Pakistan are trying to attain their competitive advantage by providing excellent quality innovation-based services to its customers (Ahmed and Humayun, 2010). The population of this study includes employees working in private banks of Pakistan. 150 employees from different branches of private banks were targeted through convenience sampling. Questionnaires were distributed and voluntarily filled by respondents. Moreover, while data 
International Journal of Innovation, Creativity and Change. www.ijicc.net

Volume 15, Issue 8, 2021

collection, the study ensured respondents that all of their data will be kept confidential and will not be disclosed.

\section{Instrument}

The five-points Likert scale was used in questionnaire range from strongly disagree to strongly agree (1-5) for this research.

\section{Measures}

\section{Transformational leadership}

For measuring transformational leadership dimensions, 13 items of (Bass and Avolio, 1995). MLQ is adopted. Respondents are briefed to rate their manager roles by means of a Likert scale that is strongly disagree to strongly agree. For instance, items were "my supervisor encourages me to perform creative tasks," "My supervisor motivates me toward challenging yet new ideas generation."

\section{Knowledge Sharing}

For measuring knowledge sharing, three items are adapted from (lu, Leung, andKoch, 2006) which required participants to rate statements by using measuring scale which starts from strongly disagree to strongly agree.

\section{Creative Self-Efficacy}

3items are used for measuring creative self-efficacy that is taken from (Tierney and farmer 2002). Respondents are briefed to rate statements regarding their self- efficacy by using Likert scale. Item is "I am confident in developing creative ideas.

\section{Employee Creativity}

For measuring employee creativity, we have adopted 13 items (Zhou and George, 2001). This Likert scale is based on character which starts from "not at all characteristic" (1) to "very characteristics" (5).

\section{Control Variable}

Control variables are those variables that are not part of this model, but they affect, e.g., demographics. So, we have to control the demographics as it has some definite impact on dependent variables. 


\section{Dummy}

150 questionnaires were given to males and female employees in the private banking sector of Rawalpindi and Islamabad in which demographically 31.3\% were between the age of 24 to 30, $44.7 \%$ of employees were between the age of 31 to 35 , and $24.0 \%$ were $36-40.43 \%$ of employees were male, and $56.7 \%$ female. $27.3 \%$ of employees have done BS, $55.3 \%$ of employees have done M.S./MPhil, and $14.0 \%$ were Ph.D. $60 \%$ of employees have permanent jobs, and $38.7 \%$ have contract jobs with a typical experience of 9 years.

\section{Analysis}

\section{Reliability Test Results}

Cronbach's Alpha Test helps to measure the internal consistency or reliability. We apply this test here to know the reliability. The 32 questionnaires met the necessary limit (greater than 0.7 for 7-10 items, and less than 0.5 for 3-5 items). Questionnaire that would have less than 0.5 for the items would not be considered for examination and would require further modification of the research paper's questionnaire. These are the following results:

\begin{tabular}{lll}
\hline Variables & Items & Coefficients \\
\hline Transformational Leadership & 13 & 0.895 \\
\hline Creative Self Efficacy & 3 & 0.773 \\
\hline Employee Creativity & 10 & 0.914 \\
\hline Knowledge Sharing Culture & 3 & 0.794 \\
\hline
\end{tabular}

The Cronbach Alpha result for the transformational leadership variable was 0.895, which was greater than 0.7 , which means the variables were above the required limit, specifying that they were consistent for the study. Cronbach Alpha result for Creative Self Efficacy variables was 0.773, which was greater than 0.7 , which specify that the variables were above the required limit, which means that they were consistent or viable for the study. Employee Creativity variables were 0.914 , which was also greater than 0.7 , which shows that the items/ variables were above the required limit, which means that were consistent for the study. Knowledge Sharing Culture variables were 0.794, which was greater than 0.7, which indicates that variables were above the required limit, which means that were consistent for the study. So, all the variables are reliable for the study. 
International Journal of Innovation, Creativity and Change. www.ijicc.net

Volume 15, Issue 8, 2021

\section{Demographic Information}

Table beneath presents the classification of participants by gender. According to the results $43.3 \%$ were male, as compared to $56.7 \%$ who were female. Further classification of respondents based on their age groups. The analysis categorized respondents in terms of specific age groups. Those employees falling under the age group of $24-30$ years were $31.3 \%$. The ages of 31-35 years were $44.7 \%$, while the age groups of $36-40$ years were $24 \%$. Education is the basic employment entry in most organizations. This study analyzed the respondents' details of qualifications. $27.3 \%$ of the participants had a qualification of undergraduate, followed by postgraduate education at $55.3 \%$. $14 \%$ of the respondents qualified for Ph.D., and $3.3 \%$ of respondents belonged to different qualifications. The respondents were categorized in terms of the duration they have served the organization. $7.3 \%$ had been worked in the organization for 3-4 years, 5.3\% had been there for 5- 6 years, $56.7 \%$ for 7-8 years, and 30.7 $\%$ for nine years and above. Therefore, very familiar with the organization, which subsequently made them valid respondents for the study. The respondents in the positions they hold in their respective organizations. The results indicate that $60.7 \%$ of the respondents had a permanent job, $38.7 \%$ had contract jobs, while .7\% of the respondents belong to other states.

\begin{tabular}{llrr}
\hline & & Frequency & Percent \\
\hline Gender & Male & 65 & 43.3 \\
\hline Age & Female & 85 & 56.7 \\
\hline & $24-30$ & 47 & 31.3 \\
\hline Education Level & $31-35$ & 67 & 44.7 \\
\hline & $36-40$ & 36 & 24.0 \\
\hline & BS & 41 & 27.3 \\
\hline Mork Duration & Master/MS/M.Phil. & 83 & 55.3 \\
\hline & Ph.D. & 21 & 14.0 \\
\hline & Other & 5 & 3.3 \\
\hline \multirow{2}{*}{ Job Status 4 years } & 5 to 6 years & 11 & 7.3 \\
\hline & 7 to 8 years & 8 & 5.3 \\
\hline & 9 years and above & 46 & 56.7 \\
\hline & Permanent job & 91 & 30.7 \\
\hline
\end{tabular}

\section{Correlation}

Table below explain that Transformational Leadership is correlated positively and significantly with Creative Self Efficacy $(r=0.773, p=0.00)$, Transformational Leadership positively 
International Journal of Innovation, Creativity and Change. www.ijicc.net

Volume 15, Issue 8, 2021

correlated with Knowledge Sharing $(\mathrm{r}=0.685, \mathrm{p}=0.00)$. It also indicates that the transformational leadership style is correlated positively and significantly with employee creativity $(\mathrm{r}=0.805, \mathrm{p}=0.00)$. The result presents that elevated level of transformational leadership style among managers of private banks in twin cities will increase Creative selfefficacy, knowledge sharing culture, employee creativity. The result shows that if managers use the transformational leadership style, the employees' creative self-efficacy will be higher. If managers use the transformational style, the knowledge sharing level among employees will be higher. If the bins of banks will use transformational leadership, employee creativity will be high.

\begin{tabular}{lllllll}
\hline & Mean & SD & $\mathbf{1}$ & $\mathbf{2}$ & $\mathbf{3}$ & $\mathbf{4}$ \\
\hline TL & 3.38 & 0.78 & $\mathbf{( 0 . 8 9 5 )}$ & & & \\
\hline CSE & 3.42 & 0.94 & $.773^{* *}$ & $\mathbf{( 0 . 7 7 3 )}$ & & \\
\hline KS & 3.57 & 0.87 & $.685^{* *}$ & $.644^{* *}$ & $\mathbf{( 0 . 7 9 4 )}$ & \\
\hline EC & 3.44 & 0.90 & $.805^{* *}$ & $.776^{* *}$ & $.683^{* *}$ & $\mathbf{( 0 . 9 1 4 )}$ \\
\hline
\end{tabular}

\section{Hypotheses Testing}

\section{Transformational leadership and Employee Creative Performance}

H1: Transformational leadership has a positive relationship with employee creativity.

The following table below demonstrates the outcomes of regression analysis. Based on the value of $\mathrm{R}$ square (0.647) indicates that $64.7 \%$ of employee creativity is ascribed to transformational leadership. The results from ANOVA show that there is important or significant relationship among transformational leadership and employee creativity $\mathrm{F}(1,148)$ $=271.771, \mathrm{p}<=0.000)$. The results further present that employee creativity is significantly influenced by transformational leadership (16.485, $\mathrm{p}<=0.000)$. Therefore, hypothesis 1 is accepted, indicating "Transformational leadership has a positive relationship with employee creativity."

\begin{tabular}{llllll}
\hline Relationship & R2 & Beta & t-value & F value & p-value \\
\hline $\boldsymbol{T L} \rightarrow \boldsymbol{E C P}$ & 0.647 & 0.805 & 16.485 & 271.771 & 0.000 \\
\hline
\end{tabular}

\section{Transformational Leadership and Creative Self-Efficacy}

H2: Transformational leadership will have a positive impact on Creative Self-efficacy. 
The results in the table below indicate the results of the regression analysis. Based on the value of $\mathrm{R}$ square (0.597) specifies that $59.7 \%$ of creative self-efficacy is attributed to transformational leadership. The results from ANOVA indicate that there is a significant relationship among transformational leadership and employee creativity $\mathrm{F}(1,148)=219.057$, $\mathrm{p}<=0.000$ ). The result presents that Creative Self efficacy significantly influenced by transformational leadership (14.801, $\mathrm{p}<=0.000)$. Therefore, hypothesis 2 of the study is accepted, indicating "Transformational leadership has a positive relationship with Creative Self-efficacy."

\begin{tabular}{llllll}
\hline Relationship & R2 & Beta & t-value & F value & p-value \\
\hline $\boldsymbol{T L} \rightarrow \boldsymbol{C S E}$ & 0.597 & 0.773 & 14.801 & 219.057 & 0.000 \\
\hline
\end{tabular}

Findings in the table below indicate the outcomes of the regression analysis. On the basis of value of R Square (0.603) indicates that $60.3 \%$ of Employee Creativity is attributed to Creative Self Efficacy. The ANOVA result indicates that there is a significant relationship among Creative Self-Efficacy and Employee Creativity F $(1,148)=224.443$, $p<=0.000)$. The results further present that employee creativity is significantly influenced by creative self-efficacy (14.981, $\mathrm{p}<=0.000$ ). Therefore, hypothesis 2 is accepted, indicating "Creative Self-efficacy has a positive relationship with Employee creativity."

\begin{tabular}{llllll}
\hline Relationship & R2 & Beta & t-value & F value & p-value \\
\hline $\boldsymbol{C S E} \rightarrow \boldsymbol{E C}$ & 0.603 & 0.776 & 14.981 & 224.443 & 0.000 \\
\hline
\end{tabular}

\section{Mediating role of Creative Self- Efficacy}

\section{H3: Creative Self -Efficacy mediates between Transformational Leadership and Employee Creativity.}

The first step is to check the impact of Transformational Leadership on Employee Creative Performance. The regression model presents the value of Transformational leadership on creative self-efficacy. The values $\beta=0.9382, p=0.000$ shows a significant relationship between Transformative Leadership and Self-efficacy. The second step is to check the effect of creative self-efficacy on employee creative performance; the results show that $(\beta=0.3637, p=0.000)$ shows a significant relationship. The third step is to check the relationship between Transformational Leadership and Employee Creative performance. The values $\beta=0.9264$, $\mathrm{p}=0.000$ show there is a significant relationship between Transformational Leadership and Employee Creative Performance. The fourth step is to check the effect of the mediating variable on IV and DV. The results show a significant effect of Transformational Leadership on Employee Creative Performance through CSE $(\beta=0.5852, p=0.000)$. Therefore, hypothesis 3 is accepted. 


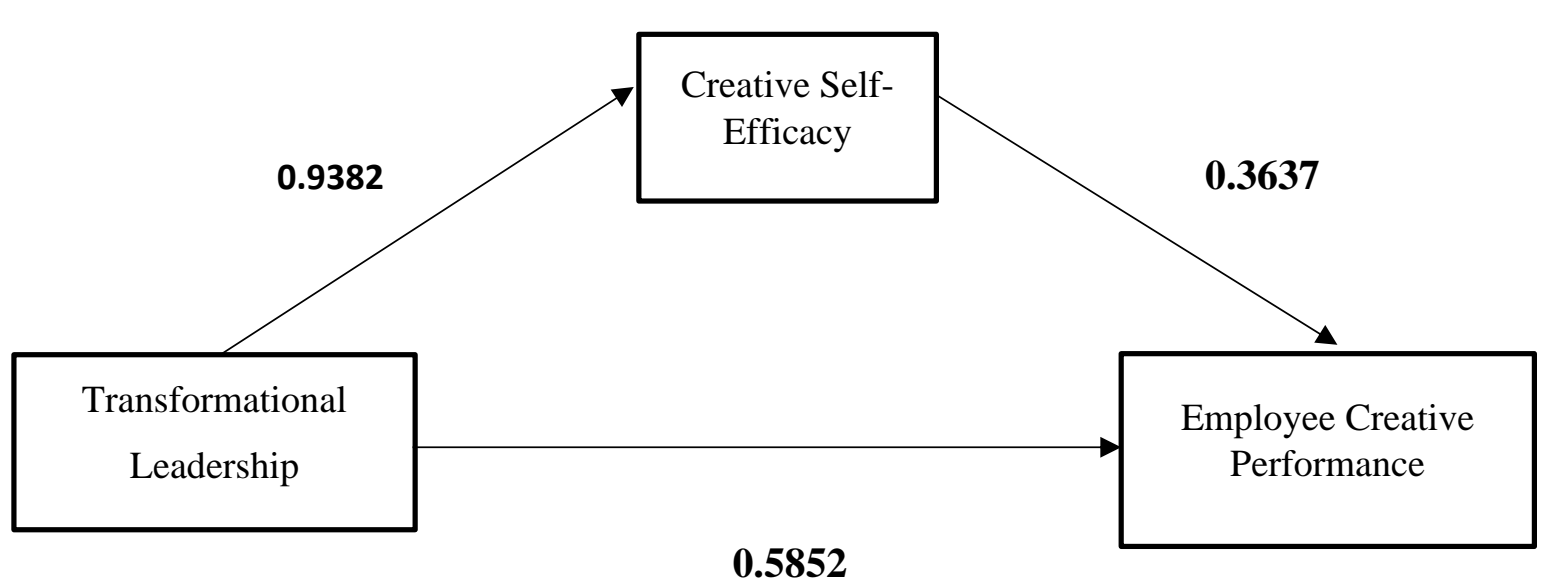

The indirect effect was examined by using the non-parametric bootstrapping. according to the results, the zero does not fall between lower and upper bound of 95\% confidence interval; the results indicate that it doesn't have direct influence $(\mathrm{IE}=0.3412)$ is statistically significant: $95 \% \mathrm{CI}=(0.2013,0.4962)$. Therefore, we accept the hypothesis 3 which states that "Creative Self-Efficacy mediates between Transformational Leadership and Employee Creativity."

\begin{tabular}{llccccc}
\hline & & Effect & S. E & $\boldsymbol{t}$ & LLCI & ULCI \\
\hline \multirow{2}{*}{ LMX } & Direct Effect & 0.5852 & .0810 & 7.2260 & .4251 & .7452 \\
\hline & Indirect Effect & .3412 & .0760 & & .2013 & .4962
\end{tabular}

\section{Moderating Role of Knowledge Sharing}

H4: Knowledge Sharing moderates the relationship of Transformational Leadership and Creative Self-Efficacy such that both have a stronger relationship when it is high instead of low.

To evaluate the moderation, the assumptions of Baron and Kenny (1986) were used. The main influence of IV, including the moderator on DV, was evaluated; and in the last segments, the interaction term was introduced. The table shows the effect of moderation of Knowledge Sharing between the relationship between Transformational Leadership and Creative SelfEfficacy. It shows the impact of TL $(\beta=0.235, \mathrm{t}=2.260, \mathrm{p}=0.025)$ and $\mathrm{KS}(\beta=0.164, \mathrm{t}=2.521$, $\mathrm{p}=0.013$ ) are significant. The overall model is also significant $(0.000)$. The result proposes that knowledge Sharing moderates the link among Transformational Leadership and Creative SelfEfficacy $(\beta=0.082 ; \mathrm{t}=4.703 ; \mathrm{p}=0.000)$. Thus, $\mathrm{H} 4$ of the study is supported. 
International Journal of Innovation, Creativity and Change. www.ijicc.net

Volume 15, Issue 8, 2021

\begin{tabular}{lccccccc}
\hline & Effect & S. E & $\boldsymbol{\beta}$ & $\boldsymbol{t}$ & $\mathbf{p}$ & LLCI & ULCI \\
\hline $\begin{array}{l}\text { Transformational } \\
\text { Leadership }\end{array}$ & 0.270 & 0.120 & 0.235 & 2.260 & 0.025 & 0.034 & 0.507 \\
\hline $\begin{array}{l}\text { Knowledge } \\
\text { Sharing }\end{array}$ & 0.164 & 0.065 & 0.158 & 2.521 & 0.013 & 0.035 & 0.292 \\
\hline TL x KS & & & & & & & \\
\hline
\end{tabular}

Note: $* \mathrm{p}<.05, * * \mathrm{p}<.01$

\section{Results}

The purpose of the research was to study the effect of transformational leadership on employee creative performance with mediating role of creative self-efficacy. Furthermore, to examine the knowledge sharing culture moderating role between transformational leadership and creative self-efficacy. The data is collected from the employees of private banks who are working with the twin cities Islamabad and Rawalpindi. $43 \%$ of employees were male, and $46 \%$ were female, with the highest percentage of age (44.7\%) was 31-35 years. Whereas the highest education level (55\%) was Masters and M.S.

To check the hypothesis, regression analysis was performed to check the relationship between transformational leadership and employee creative performance, and their result was significant in hypothesis 1 . In hypothesis 2, the association between transformational leadership and creative self-efficacy was checked, which was significant. In hypothesis 3, the mediating effect of creative self-efficacy between transformational leadership and employee creative performance was examined, which was also significant. In hypothesis 4, the moderation effect of knowledge sharing culture was examined, which was not significant which means that knowledge sharing culture doesn't moderate the relationship of transformational leadership and creative self-efficacy.

\section{Discussion and implications}

Like various other economies, Pakistani economy is also growing very rapidly and organizations. The organizations are exploring those type of leaders who lead the organization from front and have visionary capabilities in themselves so that they can enhance (CSE) creative self-efficacy among their subordinates. This study aims to determine that whether the transformational leaders can enhance the creative self-efficacy among their subordinates or not and whether they foster employee creativity regarding their job tasks, because in this competitive business environment, creativity is very essential for accomplishing competitive advantage. This paper aims to expand the existing literature on banking sector of Pakistan and 
this is the first study which explains the relation among transformational leadership and employee creativity in banking sector, particularly in Pakistan.

The very first finding of the paper exposed that there is significant as well as positive relation among transformational leadership and the employee creativity. The results of present research support the findings of Wang, Tsai and Tsai (2014). The results of this paper recommend that the transformational leaders not only boost creativity of their employees but also enhance the creative environment at workplace. In order to outperform among the boosting competition in banking sector, the organizations need creative employees to get the sustainable competitive position. It is very essential for the heads of organizations to have comprehensive knowledge about the transformational leadership effect on employee creativity level. Therefore, heads of banks should adopt the style of transformational leadership as this is one of the ways through which they boost and develop the creative competencies and skills among their subordinates. These leaders can set some example for their subordinates and can be their role model by motivating their employees to be competent and creative. Moreover, they can also enhance their employee's skills regarding creativity. The creativity skills of employees develop more technical as well as observational skills among them that help them in achieving mastery in their respective field.

Second finding of the paper exposed that there is positive as well as significant relation among transformational leadership and creative self-efficacy. The results of this research are in line with previous research conducted by Jaiswal and Dhar (2015) who indicated that transformational leaders encourage their subordinates to produce creative and innovative job outcomes and to believe that they are creatively engaged in organization. This creativity helps in developing creative self-efficacy among employees. High level of creative self-efficacy is very essential for employees and is considered as primary tool for developing their creative skills. The paper findings also highlighted that if creative self-efficacy is strengthened among employees, it can boost their creativity level for completing specific task. Moreover, this study adds knowledge to existing literature as it integrates transformational leadership theory and creative self-efficacy. The findings also disclosed that enthusiasm of transformational leaders support their subordinates to work creatively by recognition and compensation system of organization. Moreover, it also provides support to employees who believe that they have competencies to produce positive outcomes for their organization.

Third finding of this paper highlights that the relation among transformational leadership and creativity of employees is significantly mediated by creative self-efficacy and this finding extends the results of past researches (i.e., Jaiswal and Dhar, 2015; Khattak, Batool and Haider, (2017). Moreover, the finding also recommend that workers must trust in their competencies and improve their self-determination in order to generate creative results. The mediator of creative self-efficacy basically refers to employee's intrinsic aspiration to be more innovative and creative. Therefore, heads as well as management of Banking sector should understand the importance of employee's creativity for attaining competitive advantage. Moreover, it is also 
essential for the managers to learn about the association among the transformational leadership, creativity of employees and their creative self-efficacy. Hence, it has been recommended to the banking sector to make extra efforts for the training of their employees and give their employees confidence for enhancing their creative abilities. Moreover, training followers in order to transform them into transformational leaders, the banking organizations should help their workforce to accomplish the creative outcomes by enhancing their engagement as well as self-confidence so that they can effectively done their tasks. The creativity level of employees is enhanced through massive sharing of knowledge, and this study also revealed through transformational leaderships and employee creative self-efficacy that the creativity of employees can only be improved when they believe that their knowledge sharing can enhance the creativity level of their outcomes. This study also exposed the results that are consistent with those of previous studies that strong believe about knowledge sharing can enhance creative outcomes.

Finally, the empirical model of this study investigated the knowledge-sharing behavior of workers working in banking sector in relation among transformational leadership, creative selfefficacy and creativity of employees. The findings are supported with outcomes of social learning theory which demonstrates that knowledge-sharing behaviour in organizational context enhance the creative performance among employees when transformational leaders foster such behaviour (Bandura, 1977; Koh, Lee and Joshi, 2019). This approach of presented study fills the gap of previous researches by analyzing overall procedure as well as dynamics among the knowledge-sharing behavior causes and its outcomes (such as, employee creativity). Moreover, this model has also added an empirical research on the existing literature regarding knowledge sharing, creative self-efficacy and the creativity of employees in banking sector Pakistan. Thus, it has been recommended to the organizations that they should take measure to enhance their supervisor's awareness and also motivate them to build good and loyal relations with their followers. These good relations will lead the management to transformational leadership and as a result, they become capable of developing knowledge-sharing and creative behaviors among their employees. This creativity also boosts the employee's morale and thus they give their best to their respective firms.

\section{Theoretical Implications}

This research contributes to the previous literature by providing support to the area of research. The main contribution of this research is establishment of moderating role of Knowledge Sharing between the relationship of transformational leadership and the creativity of employee. Theoretically the findings of research imply that creativity of employees could be led by transformational leader and this relationship is strengthening when there is knowledge sharing orientation provided by the transformational leader. On the basis of these findings, the characteristics of transformational leaders could be extended by accommodating the needs of creative employees in context of service industry. This research is significant for the 
academicians in various ways. This study tested the moderating role of knowledge sharing between the relationship of transformational leadership and creativity of employees which has been proven significant via interaction effect. When the leaders encourage knowledge sharing among employees, it drives them to become more creative and innovation by generating new ideas.

\section{Managerial Implications}

The findings indicate that managers should consider provision of environment for the people where change is encouraged and acceptable. The employees should believe that change is necessary and beneficial for them and their organization. This is done when employees are part of decision-making process. The managers should promote new beliefs among employees and encourage their input. The management should take suggestions from employees and implement their ideas. The knowledge sharing culture should be promoted by managers in their departments and allow employees to communicate and interact. This interaction and communication will lead towards exchange of ideas and information, provide new perspectives on organizations problems and enhance effective solutions. In current competitive environment of business, employee creativity has become an essential way through which organizations get competitive edge. This is also vital for head of organizations to have comprehensive knowledge regarding the relation among different styles of leadership and the employee creativity. Therefore, the managers of banks should adopt the knowledge sharing culture and the style of transformational leadership and should establish effective relations with subordinates.

It has been analysed that the leadership styles that enhance the behavior of knowledge sharing in co-workers are likely to enhance the creativity level of employees. Sometimes, employees avoid to share knowledge with co-workers because they are concerned that they might reveal some propriety information. Therefore, in order to solve this issue, a detailed discussion should be arranged in order to determine that which type of knowledge must be shared. Moreover, some sessions/ programs must be arranged in which the significance of knowledge sharing should be discussed in order to encourage this behavior in employees and leaders. Hence, this study determines the transformational leadership as one of effective way to enhance the creative competencies of workers and to get best ways to solve the problems. As banking sector is basically employee-intensive and therefore it is essential to gain employee's confidence in order to obtain creative outcomes. Moreover, the findings of this paper exposed that two important factors through which employee creativity can be enhanced, one is knowledge sharing and other is creative self-efficacy, as these two factors enhance the confidence of employees to perform specific task creatively.

\section{Limitations and directions for future research}

This paper has also some limitations just like various other researches. First and foremost, limitation is related to time and cost and the sample groups that was limited to twin cities, 
Pakistan. Therefore, the results can't be generalized for banking sector in other geographical regions of Pakistan. Second limitation is that the survey based on self-reports. Though, researcher attempted to control the common biasness, however there are huge chances for the inflated relationship due to variance of common method. Finally, the causal relation among variables should be interpreted vigilantly. The future researches can be conducted for investigating the transformational leadership impact on employee creativity by using longitudinal or experiment design of research. As the researcher only examined these variables in Banking sector in twin cities, Pakistan, therefore findings of this study can't be realistic for other sectors. Thus, to apply the research finding on all sectors or large companies, the future researchers should collect data from various industries of Pakistan.

\section{Conclusion}

To conclude, the main aim of this study is to find that how the transformational leadership influence the employee creativity, specifically in banking sector in Pakistan. This paper also adds more knowledge to the existing literature by mediating these two variables by creative self-efficacy and by moderating these variables with the knowledge sharing behavior. As organizations spent much money on the skill and competency development of their employees and this paper has revealed the answers regarding employee creativity questions. Moreover, this paper will motivate other organizational investigators to further research on this topic and develop novel insights that help banks. To conclude, bank managers must use various technologies to improve employee creativity and adopt different opportunities to enhance their competencies (while this needs modern tools). In addition, if the clear vision about how to enhance creativity in employees is developed in the leaders than it proves very beneficial for organizations. It has been recommended that new solutions by employees should be encouraged to enhance innovativeness. Moreover, different training programs should be arranged for employees such as creative motivation techniques or brainstorming in order to examine organizational issues from various angles. The employees should also give promotions and other opportunities by determining their extent of participating in various training programs. Moreover, organizations should adopt various techniques to encourage employees to take part in these training programs. The employees should be provided by the tools through which they can implement their creative ideas at workplace. A clear image about the process through which creative skills can transfer to subordinates helps in developing effective leaders in organization. Therefore, managers should understand their employee's need to enhance the creative capabilities, effectiveness, loyalty and commitment of employees for organization. It should be clear to the organization's management that the performance of the employees will enhance when they are given challenging tasks and the sense of high expectations. The employee's creativity level should also be enhanced by increased their participation in formulation of company's vision, mission statements and various strategies. Transformational leaders encourage their subordinates to think in different ways and explore their own thinking to develop some creative solutions. Thus, if the heads of the organizations 
adopt the transformational style of leadership and provide an open work environment to their subordinates than the creativity level of employees must enhanced. The findings of this paper support the research hypothesis that the variable learning orientation significantly act as moderator among the relation of transformational leadership and the creativity level of employees. Therefore, this study adds new knowledge to literature about the transformational leadership effect on employee creativity with learning orientation variable as moderator. 
International Journal of Innovation, Creativity and Change. www.ijicc.net

Volume 15, Issue 8, 2021

\section{REFERENCES}

Afsar, B., \& Masood, M. (2018). Transformational leadership, creative self-efficacy, trust in supervisor, uncertainty avoidance, and innovative work behavior of nurses. The Journal of Applied Behavioral Science, 54(1), 36-61.

Ahmad, A., Malik, M. I., and Humayoun, A. A. (2010). Banking developments in Pakistan: A journey from conventional to Islamic banking. European Journal of Social Sciences, 17(1), 12-17.

Alameri, M., Ameen, A., Khalifa, G. S., Alrajawy, I., \& Bhaumik, A. (2019). The mediating effect of creative self-efficacy on the relation between empowering leadership and organizational innovation. Revolution, 4, 5 .

Al-Husseini, S., El Beltagi, I., and Moizer, J. (2019). Transformational leadership and innovation: the mediating role of knowledge sharing amongst higher education faculty. International Journal of Leadership in Education, 1-24.

Andriani, S., Kesumawati, N., \& Kristiawan, M. (2018). The influence of the transformational leadership and work motivation on teachers performance. International Journal of Scientific \& Technology Research, 7(7), 19-29.

Bandura, A. (1986). The explanatory and predictive scope of self-efficacy theory. Journal of social and clinical psychology, 4(3), 359-373.

Bandura, A. (2001). Social cognitive theory: An agentic perspective. Annual review of psychology, 52(1), 1-26.

Barron, F., and Harrington, D. M. (1981). Creativity, intelligence, and personality. Annual review of psychology, 32(1), 439-476.

Bass, B. M., and Bass Bernard, M. (1985). Leadership and performance beyond expectations.

Buil, I., Martínez, E., \& Matute, J. (2019). Transformational leadership and employee performance: The role of identification, engagement and proactive personality. International Journal of Hospitality Management, 77, 64-75.

Carmeli, A., Atwater, L., and Levi, A. (2011). How leadership enhances employees' knowledge sharing: the intervening roles of relational and organizational identification. The Journal of Technology Transfer, 36(3), 257-274.

Chaubey, A., Sahoo, C. K., \& Khatri, N. (2019). Relationship of transformational leadership with employee creativity and organizational innovation: A study of mediating and moderating influences. Journal of Strategy and Management.

Christensen-Salem, A., Walumbwa, F. O., Hsu, C. I. C., Misati, E., Babalola, M. T., and Kim, K. (2020). Unmasking the creative self-efficacy-creative performance relationship: the 
International Journal of Innovation, Creativity and Change. www.ijicc.net

Volume 15, Issue 8, 2021

roles of thriving at work, perceived work significance, and task interdependence. The International Journal of Human Resource Management, 1-27.

Dhar, R. L. (2015). Transformational leadership and employee creativity. Management Decision, 53(5), 894-910.

Dvir, T., Eden, D., Avolio, B. J., and Shamir, B. (2002). Impact of transformational leadership on follower development and performance: A field experiment. Academy of management journal, 45(4), 735-744.

Eisenbeiss, S. A., Van Knippenberg, D., \& Boerner, S. (2008). Transformational leadership and team innovation: integrating team climate principles. Journal of applied psychology, 93(6), 1438.

Farmer, S. M., Tierney, P., \& Kung-Mcintyre, K. (2003). Employee creativity in Taiwan: An application of role identity theory. Academy of management Journal, 46(5), 618-630.

Gist, M. E., and Mitchell, T. R. (1992). Self-efficacy: A theoretical analysis of its determinants and malleability. Academy of Management Review, 17(2), 183-211.

Golden III, J. H., and Shriner, M. (2019). Examining relationships between transformational leadership and employee creative performance: the moderator effects of organizational culture. The Journal of Creative Behavior, 53(3), 363-376.

Gong, Y., Huang, J. C., and Farh, J. L. (2009). Employee learning orientation, transformational leadership, and employee creativity: The mediating role of employee creative selfefficacy. Academy of management Journal, 52(4), 765-778.

Gumusluoglu, L., and Ilsev, A. (2009). Transformational leadership, creativity, and organizational innovation. Journal of business research, 62(4), 461-473.

Guo, L., Decoster, S., Babalola, M. T., De Schutter, L., Garba, O. A., and Riisla, K. (2018). Authoritarian leadership and employee creativity: The moderating role of psychological capital and the mediating role of fear and defensive silence. Journal of Business Research, 92, 219-230.

Henker, N., Sonnentag, S., \& Unger, D. (2015). Transformational leadership and employee creativity: The mediating role of promotion focus and creative process engagement. Journal of Business and Psychology, 30(2), 235-247.

Herrmann, D., and Felfe, J. (2013). Moderators of the relationship between leadership style and employee creativity: the role of task novelty and personal initiative. Creativity Research Journal, 25(2), 172-181.

Hirst, G., Van Dick, R., and Van Knippenberg, D. (2009). A social identity perspective on leadership and employee creativity. Journal of Organizational Behavior: The 
International Journal of Innovation, Creativity and Change. www.ijicc.net

Volume 15, Issue 8, 2021

International Journal of Industrial, Occupational and Organizational Psychology and Behavior, 30(7), 963-982.

Hu, B., and Zhao, Y. (2016). Creative self-efficacy mediates the relationship between knowledge sharing and employee innovation. Social Behavior and Personality: an international journal, 44(5), 815-826.

Jaiswal, N. K., \& Dhar, R. L. (2015). Transformational leadership, innovation climate, creative self-efficacy and employee creativity: A multilevel study. International Journal of Hospitality Management, 51, 30-41.

Jaussi, K. S., and Dionne, S. D. (2003). Leading for creativity: The role of unconventional leader behavior. The Leadership Quarterly, 14(4-5), 475-498.

Khattak, S. R., Batool, S., \& Haider, M. (2017). Relationship of leadership styles and employee creativity: A mediating role of creative self-efficacy and moderating role of organizational climate. Pakistan Journal of Commerce and Social Sciences (PJCSS), 11(2), 698-719.

Kim, S. J., \& Park, M. (2015). Leadership, knowledge sharing, and creativity: The key factors in nurses' innovative behaviors. JONA: The Journal of Nursing Administration, 45(12), 615-621.

Koh, D., Lee, K., \& Joshi, K. (2019). Transformational leadership and creativity: A metaanalytic review and identification of an integrated model. Journal of Organizational Behavior, 40(6), 625-650.

Kremer, H., Villamor, I., \& Aguinis, H. (2019). Innovation leadership: Best-practice recommendations for promoting employee creativity, voice, and knowledge sharing. Business Horizons, 62(1), 65-74.

Kremer, H., Villamor, I., \& Aguinis, H. (2019). Innovation leadership: Best-practice recommendations for promoting employee creativity, voice, and knowledge sharing. Business Horizons, 62(1), 65-74.

Kremer, H., Villamor, I., \& Aguinis, H. (2019). Innovation leadership: Best-practice recommendations for promoting employee creativity, voice, and knowledge sharing. Business Horizons, 62(1), 65-74.

Lee, J., Yun, S., Lee, S., and Hyun, Lee, J. (2019). The curvilinear relationship between selfefficacy and creativity: The moderating role of the supervisor closes monitoring. Journal of Business and Psychology, 34(3), 377-388.

Li, G., Shang, Y., Liu, H., and Xu, Y. (2014). Differentiated transformational leadership and knowledge sharing: A cross-level investigation. European Management Journal, 32(4), 554-563. 
Liao, H., Liu, D., and Loi, R. (2010). Looking at both sides of the social exchange coin: A social cognitive perspective on the common effects of relationship quality and differentiation on creativity. Academy of Management Journal, 53(5), 1090-1109.

Liao, S. H., \& Wu, C. C. (2010). System perspective of knowledge management, organizational learning, and organizational innovation. Expert systems with Applications, 37(2), 10961103.

Lin, H. F. (2007). Knowledge sharing and firm innovation capability: an empirical study. International Journal of the workforce, 28(3/4), 315-332.

Ma, X., \& Jiang, W. (2018). Transformational leadership, transactional leadership, and employee creativity in entrepreneurial firms. The Journal of Applied Behavioral Science, 54(3), 302-324.

Mittal, S., \& Dhar, R. L. (2015). Transformational leadership and employee creativity: mediating role of creative self-efficacy and moderating role of knowledge sharing. Management Decision.

Oldham, G. R., and Cummings, A. (1996). Employee creativity: Personal and contextual factors at work. Academy of management journal, 39(3), 607-634.

Santoro, G., Bresciani, S., \& Papa, A. (2020). Collaborative modes with cultural and creative industries and innovation performance: the moderating role of heterogeneous sources of knowledge and absorptive capacity. Technovation, 92, 102040.

Tierney, P., and Farmer, S. M. (2002). Creative self-efficacy: Its potential antecedents and relationship to creative performance. Academy of Management Journal, 45(6), 11371148 .

Tierney, P., and Farmer, S. M. (2004). The Pygmalion process and employee creativity. Journal of Management, 30(3), 413-432.

Tierney, P., and Farmer, S. M. (2011). Creative self-efficacy development and creative performance over time. Journal of Applied Psychology, 96(2), 277.

Tse, H. H., To, M. L., \& Chiu, W. C. (2018). When and why does transformational leadership influence employee creativity? The roles of personal control and creative personality. Human Resource Management, 57(1), 145-157.

Wang, C. J., Tsai, H. T., \& Tsai, M. T. (2014). Linking transformational leadership and employee creativity in the hospitality industry: The influences of creative role identity, creative self-efficacy, and job complexity. Tourism management, 40, 79-89.

Wang, C. J., Tsai, H. T., \& Tsai, M. T. (2014). Linking transformational leadership and employee creativity in the hospitality industry: The influences of creative role identity, creative self-efficacy, and job complexity. Tourism management, 40, 79-89. 
Wang, P., and Rode, J. C. (2010). Transformational leadership and follower creativity: The moderating effects of identification with leader and organizational climate. Human Relations, 63(8), 1105-1128.

Wu, C. H., \& Parker, S. K. (2017). The role of leader support in facilitating proactive work behavior: A perspective from attachment theory. Journal of Management, 43(4), 10251049.

Yazhou, W. A. N. G., \& Jian, L. I. N. (2013). An empirical research on knowledge management orientation and organizational performance: the mediating role of organizational innovation. African Journal of Business Management, 7(8), 604-612.

Zhou, J., and George, J. M. (2001). When job dissatisfaction leads to creativity: Encouraging the expression of voice. Academy of Management Journal, 44(4), 682-696. 